\title{
Erratum to: The clinical characteristics of alcohol-related ocular rupture
}

\author{
Liu Jian-wei • Hu Zhen-bo • Wang Shu-na • \\ Zhu Yu-guang $\cdot$ Deng Ai-jun
}

Published online: 25 November 2014

(C) Springer-Verlag Berlin Heidelberg 2014

\section{Erratum to: Graefes Arch Clin Exp Ophthalmol \\ DOI 10.1007/s00417-014-2809-x}

The original version of this article inadvertently contained mistake in the statistical calculations.

Corrected version:

The $\chi 2$ value in "the involvement of adnexa injuries" is 9.12 but not 5.86 .

The corrected $\chi^{2}$ value does not influence the statistical significance ( $p$-value) or the conclusion of the study.

The online version of the original article can be found at http:// dx.doi.org/10.1007/s00417-014-2809-x.

L. Jian-wei $\cdot$ H. Zhen-bo $\cdot$ W. Shu-na $\cdot$ Z. Yu-guang $\cdot$ D. Ai-jun $(\bowtie)$ Department of Ophthalmology, Affiliated Hospital of Weifang

Medical University, Yu-He Street 2428, Weifang 261031, Shandong

Province, China

e-mail: wfdengaijun@163.com

L. Jian-wei

e-mail: luxuvy@163.com 